Monte Carlo integrated approach to radiological characterization for nuclear facilities decommissioning

E. Mossini ${ }^{a}$, G. Parma ${ }^{\mathrm{a}}$, F.M. Rossi ${ }^{\mathrm{a}}$, M. Giola ${ }^{\mathrm{a}}$, A. Cammi ${ }^{\mathrm{a}}$, E. Macerata ${ }^{\mathrm{a}}$, E. Padovani ${ }^{\mathrm{a}}$, and M. Mariani ${ }^{\mathrm{a}}$

${ }^{a}$ Department of Energy, Politecnico di Milano, Via Lambruschini, 4, 20156, Milano, Italy

*corresponding author: eros.mossini@polimi.it 


\title{
Monte Carlo integrated approach to radiological characterization for nuclear facilities decommissioning
}

\author{
In the last decades, hundreds of nuclear reactors have been shut-down and have \\ experienced decommissioning. This is also the case of L-54M Politecnico di \\ Milano nuclear research reactor. Since shut-down in 1979, the plant has been \\ managed following deferred dismantling strategy. Recently, preliminary \\ radiological characterizations have been launched, even though a more extended \\ campaign is necessary to implement facility decommissioning and restore \\ unrestricted reuse status.
}

In the framework of the IAEA collaborative research project on irradiated GRAphite Processing Approaches (GRAPA), a general radiochemistry and Monte Carlo integrated approach has been developed to study materials activation and support radiological characterization campaign. This integrated method, thanks to its general principles, could be applied to any nuclear reactor or facility undergoing decommissioning, thus helping to reduce the characterization efforts and, possibly, the associated costs.

Keywords: decommissioning; integrated approach; MCNP; neutron activation

\section{Introduction}

Worldwide, several nuclear reactors and facilities have experienced decommissioning in the last decades and an even larger number will require decommissioning in the next years (1). International Atomic Energy Agency defines decommissioning as all the administrative and technical actions required to obtain partial or complete removal of regulatory controls from a nuclear facility, in view of ensuring the protection of both workers, public and the environment (2). In Italy, five research reactors are still operating, while some have been definitively shut-down, such as CeSNEF (Centro Studi Nucleari Enrico Fermi) L-54M nuclear research reactor (3). It was commissioned by Politecnico di Milano to Atomics International in the late '50s and reached the first criticality in 1959 (4). This reactor was mainly operated for research and didactic 
purposes in the fields of radiochemistry, neutron fission analysis, nuclear equipment trial, material irradiation and activation analysis. The core is made of a liquid uranyl sulfate fuel solution, enriched up to $19.94 \% \mathrm{wt}$ in ${ }^{235} \mathrm{U}$, accommodated in a sphere made of nuclear grade stainless steel. A complex cooling coils system was devoted to heat removal. Furthermore, the core was crossed by a longitudinal stainless steel channel used for material irradiation and by 4 vertical stainless steel control rods, evenly spaced radially inside the core, enclosing boron carbide pellets. Besides the neutron moderation effect ensured by the aqueous fuel solution, the aluminum secondary case housing the core was filled by nuclear grade graphite (Atcheson Graphite Ordinary Temperature, from US National Carbon Company), the same used by Enrico Fermi in its Chicago Pile-1 (5). In order to reflect escaping neutrons and reduce the radiation emission, the secondary case was surrounded by a graphite stack and by heavyweight magnetitecolemanite concrete biological shield.

In 1979, the Italian Safety Competent Authority did not grant the license to continue L-54M normal operation due to the large expansion of urban fabrics around the nuclear site. Since deferred dismantling strategy was adopted, Politecnico di Milano had to guarantee safe condition of the site in order to keep the plant under radiological control until accomplishment of decommissioning activities (2, 6-7). The choice of this strategy was imposed by the absence of national repository to host radioactive waste, as well as by some legislative gaps (8-9). On the other hand, deferred dismantling is endowed with several advantages (10-12). Since shut-down, in order to pursue the facility safe storage and the safety of workers and public, Politecnico di Milano carried out several activities in compliance with International well-established guidelines (6-7, 10, 13), National Legislative Decree (14) and Safety Competent Authority. In particular, the spent nuclear fuel solution was accommodated into a well-shielded tank and sent out 
for reprocessing. As well, Ra-Be neutron start-up source was transferred from the graphite pile to a suitable neutron-shielded container and moved away from the plant. Furthermore, suitable acidic cleaning solutions were used for primary circuit decontamination and then processed by ion exchange resins. In 2001, the secondary case envelope containing the core and all components connected to it was moved to a dedicated and well-shielded container and in-situ safely stored.

In 2014, in view of launching dismantling operations, Politecnico di Milano started radiological campaigns for the pre-characterization of systems, structures, components, and surroundings belonging to L-54M reactor. Characterization actions are currently being carried out not only during pre-decommissioning, but also during other stages of nuclear facility decommissioning (15-16). On the other hand, at the earlier stage, the main purpose is the collection of the necessary information to assess the radiological status of the facility, i.e. by determining radionuclides inventories, associated potential radiation exposures and risks to workers, public, and environment. In this regard, in order to assess unrealistic contamination of the surrounding area and obtain the reference radiological blank for the future dismantling activities, an environmental radiological characterization was carried out (17). Furthermore, with a view to preliminarily estimating radionuclides inventory and waste volume that will likely arise from upcoming decommissioning operations, a radiological precharacterization of the nuclear site was performed (18). Finally, at the end of 2016, Politecnico di Milano joined IAEA collaborative research project on irradiated GRAphite Processing Approaches (GRAPA), with the purpose of achieving a detailed radiological characterization of L-54M graphite moderator and reflector (19). All the gathered data will support the planning of forthcoming decommissioning actions. At the same time, the decommissioning costs evaluation cannot disregard expenditures due to 
radiological characterization campaigns, which are time and money consuming by their nature $(12,16)$. In view of better addressing the future radiological characterization efforts and reducing the associated costs, the main contribution to GRAPA project is the development of a Monte Carlo approach to accurately assess neutron activation of the graphite pile occurred during 20 years of reactor operations. In fact, probabilistic based codes, above all Monte Carlo, proved to be well suited to model neutron activation and assess radionuclides inventory in case of activation contribution prevailing on contamination (16). The application of this approach is preferred due to typical high dose rates of activated core materials. . In literature, this approach has already been suggested to assess neutron activation in nuclear power plants components (20). Even if to date with scarce accuracy and no systematic methodology, this approach has already proved to be promising since it would allow reducing radiological characterization efforts and cost. The pile of L-54M reactor has been proficiently modeled in detail up to the outer boundary of the concrete shielding, by retrieving most of the required data from blueprints (21), safety report (4), and academic works (22-23). The implemented neutronic model has been widely verified by comparing simulated criticality and neutron flux data with available experimental ones. Afterwards, the main production reactions of the most relevant radionuclides have been simulated and 3D activity concentration maps have been obtained and point-to-point compared with the few available experimental values in order to demonstrate validity and robustness of the developed approach.

This paper aims at stepwisely describing the developed Monte Carlo approach for neutron activation assessment, from neutronic model coding towards its verification and validation. Since the herein developed systematic approach relies on general physical principles, such as neutron diffusion and interaction with matter, it could be 
applied to any nuclear installation presenting the neutron-induced activation issue in view of mitigating pre-characterization efforts in terms of associated costs and radioprotection issues.

\section{Method}

The use of Monte Carlo based codes is recommended for three dimensional neutron transport calculations in very complex geometries, that is the case of neutron flux and activation simulation in nuclear reactors (16). Among the Monte Carlo codes (MCBEND, MORSE, KENO, and TRIPOLI above all), MCNP6 (Monte Carlo NParticle, version 6) software package was selected for the 3D modelling of L-54M reactor (24). This code was chosen since it is well-established and validated, endowed with high-level performance and reliability in reactor physics modelling, i.e. suitable to study thermal neutron diffusion and activation reaction rates, and it could be coupled with computer-aided design (CAD) and drafting software applications (25).

The approach could be divided in three different steps (see Figure 1): i) MCNP neutronic simulation of the nuclear reactor and model verification with experimental criticality and fluences data; ii) MCNP simulation of the main nuclear activation reactions to obtain reaction rates, accordingly with the radionuclides of interest; iii) processing of reaction rates to obtain activity concentrations distribution and model validation by comparing simulated activity concentrations with experimental data from radiological characterization.

[Insert Figure 1 near here] 


\section{STEP 1: MCNP simulation of nuclear reactor and model verification}

First of all, the system physical model has to be created in the Monte Carlo code, by accurately writing input file scripts that describe the system to be simulated. All geometrical (dimensions and positions) and material composition structural features, as well as the complete neutronic history of the plant, have to be implemented in dedicated input file sections, such as cell, surface and material cards. Since the correct and accurate system description by input file plays a pivotal role in the whole simulation process, several preliminary debugging tests are required. Official documents and vendor blueprints should be used to retrieve the most accurate and rigorous information on the main reactor components. In case of uncertainties, a sensitivity analysis should be carried out in order to assess the impact of such input uncertainties on model output. In order to bridge some data gaps, focused experimental analyses should be carried out. For example, impurities distribution, density and porosity information is required for achieving accurate simulation of neutrons diffusion and activation reactions. In particular, if composition data (not only macro constituents but also impurities) are not given in the available documentation, elemental characterization has to be carried out with a view to obtaining the concentration of activation precursors in pristine material. Moreover, some input script limitations need to be overlooked by careful substitution of the most complex structures into simpler ones, but guaranteeing, at the same time, the best model accuracy and point-to-point mass conservation. By way of example, the cooling coils of the primary circuit should be simplified by substituting curved components with straight ones, due to difficult implementation with the simple pre-set geometry elements available and the Boolean operations allowed in MCNP code without CAD coupling. 
Afterwards, in order to verify the model accuracy, several system properties described by the code have to be selected and compared with the available experimental values obtained during the operational years of the reactor. For example, criticality data and neutron fluxes in different core positions (such as inside the experimental exposure channels) could be used to verify the Monte Carlo model of a nuclear reactor. KCODE card is used in criticality simulations to determine neutron multiplication factor $\left(k_{e f f}\right)$ in a multiplying medium. These criticality calculations have to be properly converted into reactivity values to be compared with the corresponding experimental ones. Examples of criticality parameters that could be evaluated are:

- Subcritical reactivity evaluated by simulating the implemented reactor core with all control rods completely inserted;

- Supercritical reactivity evaluated with all control rods completely withdrawn;

- Total rod worth (i.e. the overall reactivity amount associated to the control rods set), that is the difference between Supercritical and Subcritical reactivities;

- Control rod inventory, evaluated in supercritical conditions as the difference between the reactivity value with all control rods withdrawn and the one with just a single rod inserted;

- Control rod calibration, evaluated with one control rod stepwisely moved from fully inserted to completely extracted position, while maintaining all others withdrawn.

All criticality calculations could be performed using $K C O D E$ card at ambient temperature $\left(20^{\circ} \mathrm{C}\right)$, with a sufficient number of cycles and neutrons per cycle. At least the first cycles have to be neglected since they are strongly affected by the imposed starting source distribution. The TMP card could be used to perform simulations at the 
real reactor working conditions, i.e. taking into account the correct operating temperature, by adjusting elastic scattering cross-sections and collision kinematics. However, since TMP card has no effect on absorption cross-sections and thermal scattering kernels, the total neutron reaction cross-sections have to be evaluated at the desired temperatures by the makxsf utility code and adequate molecular scattering crosssections datasets have to be chosen. $F 2$ and $F 4$ tallies are used to determine the flux of particles with determined energy averaged over a surface or volume respectively. They give a fluence expressed in $\mathrm{cm}^{-2}$. $F 7$ tally could be used to normalize the flux on the energy produced by fission events in the core region, taking into account the mass of the fuel cell and a conversion factor $(C F$, from $\mathrm{MeV}$ to $\mathrm{J})$, as shown in Eq. 1:

$$
\boldsymbol{\Phi}_{\text {norm }}\left[\mathrm{cm}^{-\mathbf{2}} \cdot \boldsymbol{J}^{-\mathbf{1}}\right]=\frac{F 2\left[\mathrm{~cm}^{-2}\right]}{F 7\left[\mathrm{MeV} \cdot \mathrm{g}^{-1}\right] \cdot F 7_{\text {mass }} \cdot C F(\mathrm{MeV} \rightarrow J)}
$$

This operation gives a normalized flux expressed in $\mathrm{cm}^{-2} \cdot \mathrm{J}^{-1}$, i.e. one of the forms in which the experimental neutron flux is usually expressed. On the other hand, another conversion could be applied by furtherly multiplying for the power produced by the reactor (expressed in $\mathrm{W}$ ), thus obtaining the most common flux formulation expressed in $\mathrm{cm}^{-2} \cdot \mathrm{s}^{-1}$.

\section{STEP 2: MCNP simulation of main nuclear reactions}

Thereafter, the main radionuclides of interest for decommissioning purposes have to be selected according to similar literature works and coherently with time elapsed from reactor shut-down. Moreover, the main neutron activation reactions have to be identified and the concentration of the respective activation precursors in virgin materials have to be known, either from available documentation or from focused experimental elemental characterization. 
In view to obtaining three-dimensional activation maps for each radionuclide of interest, several operations have to be performed. First of all, the neutron flux has to be calculated. With this regard, the whole material object of the study has to be covered by a dense rectangular mesh, e.g. with $1 \mathrm{~cm}^{3}$ single element volumes. If compared to the overall material volume, each single element volume could be considered point-like. For all these $1 \mathrm{~cm}^{3}$ volumes, the normalized neutron flux has to be obtained as above described in Eq. 1 and normalized on the deposited energy in the fuel cell. As well, a reaction rate tally has to be applied to all $1 \mathrm{~cm}^{3}$ volumes. As reported in Eq. 2, the reaction rate $(R R)$ could be obtained by multiplying precursor nuclide density $(C$, expressed in barn $\left.^{-1} \mathrm{~cm}^{-1}\right)$, cross-sections of activation reaction ( $\sigma$, expressed in barn) and neutron flux $\left(\Phi_{\text {norm }}\right.$, expressed in $\left.\mathrm{cm}^{-2} \cdot \mathrm{J}^{-1}\right)$.

$$
\boldsymbol{R R}\left[\mathrm{cm}^{-3} \cdot \boldsymbol{J}^{-\mathbf{1}}\right]=C \cdot \sigma \cdot \Phi_{\text {norm }}
$$

The resulting reaction rate is expressed in atoms per $\mathrm{cm}^{3}$ and J. Since $F 2$ tally returns the flux for the whole neutron energy spectrum, MCNP could consider both $\sigma$ and $\Phi_{n o r m}$ as functions of the neutrons energy, without restricting to only thermal neutrons.

Concerning spatial dependence, the flux is dependent on the position, while it could not be true for the precursor nuclide density. In fact, even if the elemental composition distribution within the material cannot be considered as uniform, it is impossible to know the real spatial distribution of the precursor nuclides. So, this spatial distribution was assumed as uniform.

\section{STEP 3: data processing and model validation}

Then, the reaction rate has to be multiplied by the energy produced by the reactor $\left(E_{i}\right.$, where $i$ is the $i$-th month of reactor operation and $m$ is the last month of 
reactor operation) and by a conversion factor $\left(\lambda\left[\mathrm{s}^{-1}\right] / \rho\left[\mathrm{g} \cdot \mathrm{cm}^{-3}\right]\right)$ in order to obtain activity concentration, expressed in $\mathrm{Bq} \cdot \mathrm{g}^{-1}$, for each radionuclide in all single element volumes. The activity concentrations have to be calculated by considering the identified activation reaction routes and by summing a number of contributions equal to reactor operation months, as shown in Eq. 3. Finally, the simulated activity concentration results have to be updated to the date of the radiometric measure by a decay factor, where $\Delta t_{i}$ is the time elapsed between radionuclide production during the $i$-th month of reactor operation and measurement.

$$
\boldsymbol{A}\left[\boldsymbol{B} \boldsymbol{q} \cdot \boldsymbol{g}^{-\mathbf{1}}\right]=\frac{\lambda}{\rho} \cdot \sum_{i=1}^{m} R R \cdot E_{i} \cdot e^{-\lambda \cdot \Delta t_{i}}(\text { Eq. 3) }
$$

A more detailed as possible recording of energy produced by the reactor is required in order to obtain the most accurate simulation of activation products activity concentration. By way of example, a common way to record the produced energy is based on monthly time steps. This could be a satisfactory compromise for sufficiently detailed description of the system, especially if radionuclides half-lives are far higher than the recording time step. A suited MATLAB script should be implemented, thus allowing not only to calculate the three-dimensional radionuclides activity concentration distributions, but also to conveniently plot the results and promptly compare simulated data with available experimental results.

In order to validate the model, the simulated activity concentrations have to be compared with the available radiometric measurements, accordingly with preliminary radiological characterization campaigns performed on irradiated samples of the material under investigation. Among all activation products, the Easy-to-Measure (ETM) $\gamma$-emitting radionuclides still measurable after reactor shutdown should be the first objects of the model validation. In fact, their quantification is usually endowed with 
lesser experimental uncertainty and issues with respect to the Difficult-to-Measure (DTM) radionuclides, that normally require preliminary chemical and radiochemical procedures (16). In order to allow comparison with experimental data, the activity concentrations of these ETM radionuclides in the irradiated material have to be estimated by Monte Carlo code assuming the values of stable activation precursors impurity in virgin material, as obtained by dedicated elemental characterization campaigns or historical data from the vendor or the operator.

\section{Results and Discussion}

By way of example, the experience gathered from the study of L-54M nuclear research reactor is herein reported. The above described Monte Carlo approach has been applied to assess neutron activation of nuclear grade graphite moderator and reflector. A detailed model of the L-54M reactor - including the core with the cooling coils and the fuel solution, the graphite moderator and reflector, the main exposure tubes and the heavyweight concrete biological shield - has been developed for MCNP6 code. The input file describing geometrical (dimensions and positions) and material composition structural features has been organized in three different blocks: i) cells cards; ii) surface cards; iii) data cards $(3-4,21,23)$. ENDF (Evaluated Nuclear Data File) and JEFF (Joint Evaluated Fission and Fusion) cross-section libraries were selected to run the simulations (26-27). In Figure 2, a qualitative comparison between the reactor core section obtained from vendor official blueprints (Left) and the one implemented in the code (Right) is presented. In particular, the uranyl sulfate fuel solution (in yellow) is accommodated in the spherical reactor core, along with cooling coils system, longitudinal central exposure tube (in violet the empty channel) and 4 vertical control rods (in violet the empty channel, in pink the enclosed boron carbide pellets). The overflow chamber (in blue) is located above the core. The graphite moderator (in green) 
is located within the secondary case (in orange) housing the core and surrounded by the graphite stack reflector (in green) and by concrete biological shield (not in the figure).

[Insert Figure 2 near here]

MCNP6 code has been exploited to develop a 3D neutronic model of L-54M graphite activation, in order to assess 3D-distribution of neutron activated impurities. The accomplishment of this task could have been hindered by: i) inaccurate assessment of some impurities in virgin graphite (especially nitrogen and chlorine), ii) lack of knowledge about reactor operation (especially spatial neutron fluxes distribution, material and geometry specifications). The model has already been verified with criticality and fluence data and preliminarily validated thanks to a focused radiological characterisation of few irradiated graphite samples collected along a graphite rod. Concerning criticality data, hereinafter the results of supercriticality reactivity, single and total rod worth are reported and compared with the experimental data contained in the Reactor Safety Report, see Table 1 and Table 2 (4, 22-23). All criticality simulations were performed with a minimum of 6000 neutrons per cycle and 4000 cycles, and discarding the first 30 cycles as previously described. Satisfactory agreement between simulated and literature data is shown. The differences could be attributed to lack of knowledge in the documentation, especially on absorbers, steels and alloys composition and structural dimension. Furthermore, differences between the nuclear datasets are evidenced: the core excess reactivity seems to be better predicted by JEFF-3.2 cross-section libraries, while the total rod worth by ENDF/B-VII.0 libraries. In addition, it should be pointed out that some literature data are provided without associated error and they were just calculated and not experimentally measured $(4,22)$. In any case, 
L-54M criticality condition has been reached with a control rod completely inserted and another one halfway inserted, accordingly with reactor working conditions (4).

[Insert Table 1 near here]

[Insert Table 2 near here]

Concerning fluence data, the implemented exposure channels are highlighted in Figure 3. By way of example, hereinafter, the simulated normalized thermal flux in the central exposure tube (channel 3) is reported in Figures 4 and compared with the available experimental data provided by the vendor, namely $\operatorname{Exp} 1$ (21), and by a M.Sc. thesis, namely $\operatorname{Exp} 2$ (23). The obtained results are satisfactorily consistent with the available experimental values. In fact, the simulated data are included between two different available datasets. It should be pointed out that Atomic International charts datasets are provided without associated error. These results are encouraging if the intrinsic modelling uncertainties and the unavoidably assumed approximations are taken into account. In fact, the simulated data are of the same order of magnitude of the experimental ones. Moreover, the shapes are very similar. This outcome, in particular, is very promising since it demonstrates that the main physical properties of the system are exceptionally well described by the developed neutronic model.

[Insert Figure 3 near here]

[Insert Figure 4 near here] 
Concerning radionuclides inventory, since L-54M reactor was shut-down in 1979, only graphite activation products with half-lives greater than 2 years were selected: ${ }^{3} \mathrm{H},{ }^{14} \mathrm{C},{ }^{36} \mathrm{Cl},{ }^{41} \mathrm{Ca},{ }^{55} \mathrm{Fe},{ }^{59} \mathrm{Ni},{ }^{60} \mathrm{Co},{ }^{63} \mathrm{Ni},{ }^{93} \mathrm{Mo},{ }^{94} \mathrm{Nb},{ }^{99} \mathrm{Tc},{ }^{108 \mathrm{~m}} \mathrm{Ag},{ }^{152,154} \mathrm{Eu}$, ${ }^{233} \mathrm{U},{ }^{239} \mathrm{Pu}$. Furthermore, since even nuclear grade graphite contains natural U and Th at impurity level, fission products deriving from ${ }^{235,238} \mathrm{U}$ and ${ }^{232} \mathrm{Th}$ fission events were considered. For all the mentioned activation products, the main neutron activation reactions have been identified and simulated along with fission events in order to obtain the respective reaction rates and, consequently, the activity concentrations for all $1 \mathrm{~cm}^{3}$ volumes of simulated irradiated graphite. With a view to obtaining the best accuracy from neutron activation assessment, elemental characterization of virgin L-54M graphite was performed by ICP-MS, since poor information was available from the documentations and from the literature, even if it is the same nuclear grade graphite type used by Enrico Fermi in its Chicago pile. Great attention was dedicated to the concentration assessment of neutron activation precursors, with the exception of nitrogen and chlorine that cannot be determined by the employed analytical technique.

Taking into account intrinsic modelling uncertainties and unavoidably assumed approximations, promising results have been obtained by comparing simulated and experimental ${ }^{152}$ Eu activity concentrations, see Table 3 . The choice of the ETM ${ }^{152} \mathrm{Eu}$ for the preliminary model validation was driven by a radiological characterization of few irradiated graphite samples by gamma spectrometry performed in a recent M.Sc. thesis (28). The simulated results seem to slightly underestimate the experimental data. This could be due to some modelling uncertainties and lack of knowledge in the available documentation.

[Insert Table 3 near here] 
With a view to completing the model validation and strengthen its trustworthiness, several irradiated graphite samples have already been collected at different radial and axial position with respect to the core to be analysed by gamma spectrometry to determine ETM $\gamma$-emitting radionuclides. These novel results will be compared with correspondent simulated data. In addition, concerning pure $\beta$-emitting radionuclides (above all ${ }^{3} \mathrm{H},{ }^{14} \mathrm{C},{ }^{36} \mathrm{Cl},{ }^{41} \mathrm{Ca},{ }^{55} \mathrm{Fe},{ }^{59,63} \mathrm{Ni}$ ), a dedicated radiochemical procedure will allow to determine their activity concentrations in the abovementioned irradiated graphite samples (29). The results will be used to better address the efforts of this computational approach and to accurately estimate the radionuclides inventory in the whole graphite pile. The final purpose is to find a correlation between ETM and HTM radionuclides with a view to building a scaling factor for subsequent decommissioning activities (15).

\section{Conclusion}

This integrated method, thanks to its general principles, could be applied to the radiological characterization of systems, structures and components of any nuclear reactor or facility undergoing decommissioning, thus helping to reduce the characterization efforts and, possibly, the associated costs. The integrated computational approach prompted to be a valid support to radiological characterization campaign to be performed during the preliminary decommissioning stages. In fact, it could be a very useful tool in better addressing the forthcoming decommissioning operations (decontamination, dismantling and waste management) under safer conditions for worker and public safety and environmental protection.

As a case study, L-54M neutronic model was proficiently developed, verified by 
comparing simulated and experimental criticality and fluence data, and preliminarily validated by comparing few simulated and experimental radiometric data.

\section{References}

[1] International Atomic Energy Agency (IAEA). Research reactor database: https://nucleus.iaea.org/RRDB/RR/ReactorSearch.aspx?rf=1. Vienna, Austria, 2012.

[2] International Atomic Energy Agency (IAEA). TECDOC-1478: Selection of decommissioning strategies: Issues and factors. ISBN: 92-0-111705-1. Vienna, Austria, 2005.

[3] Parkins, W.E. Aqueous Homogeneous Type Research Reactors. digital.library.unt.edu/ark:/67531/metadc1021826/m1/1/. Canoga Park, California, USA, 1958.

[4] Terrani, S. Reactor and nuclear facilities of the CeSNEF site: Safety report (in Italian: Il reattore e gli impianti nucleari del CeSNEF - Rapporto di sicurezza). Politecnico di Milano, Milano, Italy, 1961.

[5] Fermi, E. The Collected Papers of Enrico Fermi, vol. 2. Ed. E., Segre.: University of Chicago Press, Chicago, IL, USA, 1965.

[6] International Atomic Energy Agency (IAEA). Safety Reports Series No. 50: Decommissioning strategies for facilities using radioactive material. ISBN: 92-0113206-9. Vienna, Austria, 2007.

[7] International Atomic Energy Agency (IAEA). Safety Standards Series No. WS-G2.1: Decommissioning of nuclear power plants and research reactors. ISBN: 92-0102599-8. Vienna, Austria, 1999. 
[8] International Atomic Energy Agency (IAEA). Nuclear Energy Series No. NW-T1.10: Advancing implementation of decommissioning and environmental remediation programmes. ISSN: 1995-7807. Vienna, Austria, 2016.

[9] International Atomic Energy Agency (IAEA). Safety Standards Series No. WS-R2: Predisposal management of radioactive waste including decommissioning. ISBN: 92-0-100300-5. Vienna, Austria, 1999.

[10] International Atomic Energy Agency (IAEA). TECDOC-1273: Decommissioning techniques for research reactors. ISSN: 1011-4289. Vienna, Austria, 2002.

[11] International Atomic Energy Agency (IAEA). Technical Reports Series No. 463: Decommissioning of research reactors and other small facilities by making optimal use of available resources. ISBN: 978-92-0-110607-0. Vienna, Austria, 2008.

[12] Organisation for Economic Co-operation and Development - Nuclear Energy Agency (OECD-NEA). Costs of decommissioning nuclear power plants. No. 7201. Paris, France, 2016.

[13] International Atomic Energy Agency (IAEA). Safety Standards, No. GSR Part 6: Decommissioning of Facilities. ISSN: 1020-525X. Vienna, Austria, 2014.

[14] D.Lgs 230/95. Legislative Decree of Government n. 230/95 and Subsequent Modifications and Additions (in Italian: Decreto Legislativo del Governo 230/95 e Successive Modifiche ed Aggiunte - Attuazione delle direttive Euratom in materia di radiazioni ionizzanti), Italy, 17 March 1995.

[15] International Atomic Energy Agency (IAEA). TECDOC-1537: Strategy and Methodology for Radioactive Waste Characterization. ISBN: 92-0-100207-6. Vienna, Austria, 2007. 
[16] International Atomic Energy Agency (IAEA). Technical Reports Series No. 389: Radiological Characterization of Shut Down Nuclear Reactors for Decommissioning Purposes. ISBN: 92-0-103198-X. Vienna, Austria, 1998.

[17] Mossini, E.; Codispoti, L.; Giola, M.; Castelli, L.; Macerata, E.; Porta, A.; Campi, F.; Mariani, M. Topsoil radiological characterisation of L-54M reactor surroundings preliminary to decommissioning operations. J. of Environ. Radioactiv. 2017. DOI: 10.1016/j.jenvrad.2017.11.026.

[18] NUCLECO. Final report of CeSNEF Pre-Decommissioning Activities (Document written in Italian: Rapporto finale per le attivita di pre-decommissioning del CeSNEF di Milano). NUCLECO, Roma, Italy, 2016.

[19] Wickham, A.; Steinmetz, H.-J.; O'Sullivan, P.; Ojovan, M.I. Updating irradiated graphite disposal: Project GRAPA and the international decommissioning network. J. Environ. Radioactiv. 2017, 171, 34-40. DOI: 10.1016/j.jenvrad.2017.01.022.

[20] Ancius, D.; Ridikas, D.; Remeikis, V.; Plukis, A.; Plukiene, R.; Cometto, M. Evaluation of the activity of irradiated graphite in the Ignalina Nuclear Power Plant RBMK-1500 reactor. Nukleonika. 2005, 50, 113-120.

[21] Atomics International. L-54M Blueprints, 1959.

[22] Hassid, A. M.Sc. Thesis: L-54M CeSNEF reactor. Plant, start-up, control, first measurements. (in Italian: Il reattore L-54M del CeSNEF. Impianto, avviamento, controllo, prime misure.). Politecnico di Milano, Milano, Italy, 1959.

[23] Terrani, M. M.Sc. Thesis: L-54M CeSNEF reactor. Measurement of neutron flux and determination of generated power. (in Italian: Il reattore L-54M del CeSNEF. Misure di flussi neutronici e determinazione della potenza). Politecnico di Milano, Milano, Italy, 1960. 
[24] Goorley, T.; James, M.; Booth, T.; Brown, F.; Bull, J.; Cox, L.J.. Initial MCNP6 Release Overview. Nucl. Technol. 2012, 180, 298-315. DOI: 10.13182/NT11-135.

[25] Los Alamos National Laboratory. MCNP: A General Montecarlo N- Particle Transport Code. Rep. LA-12625-M. Los Alamos, NM, USA, 1993.

[26] Chadwick, M.; et al. ENDF/B-VII.0: Next Generation Evaluated Nuclear Data Library for Nuclear Science and Technology. Nucl. Data Sheets. 2006, 107, 29313060. DOI: 10.1016/j.nds.2006.11.001.

[27] Santamarina, A.; et al. The JEFF-3.1.1 Nuclear Data Library: Validation Results from JEF-2.2 to JEFF-3.1.1. Organisation for Economic Co-operation and Development - Nuclear Energy Agency, 2009.

[28] Castelli, L.; Mapelli D. M.Sc. Thesis: Decommissioning of L-54M CeSNEF reactor (in Italian: Decommissioning del reattore L-54M del CeSNEF). Politecnico di Milano, Milano, Italy, 2013.

[29] Hou, X. Radiochemical analysis of radionuclides difficult to measure for waste characterization in decommissioning of nuclear facilities. J. Radioanal. Nucl. Chem. 2007, 273, 43-48. DOI: 10.1007/s10967-007-0708-x. 


\section{Figures:}

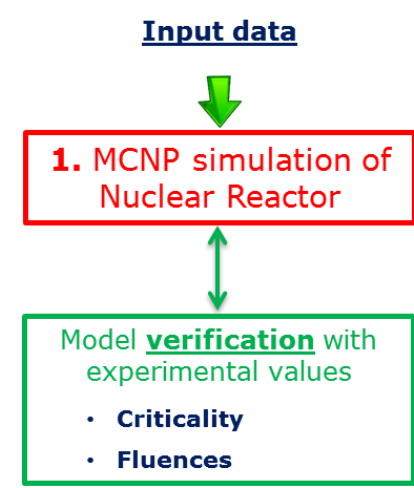

Elemental composition

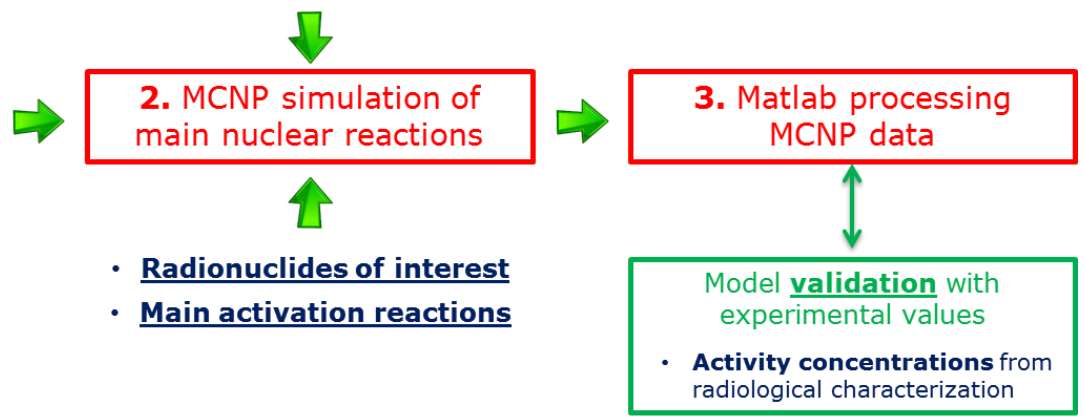

Figure 1 Sketch of the developed MCNP approach. 

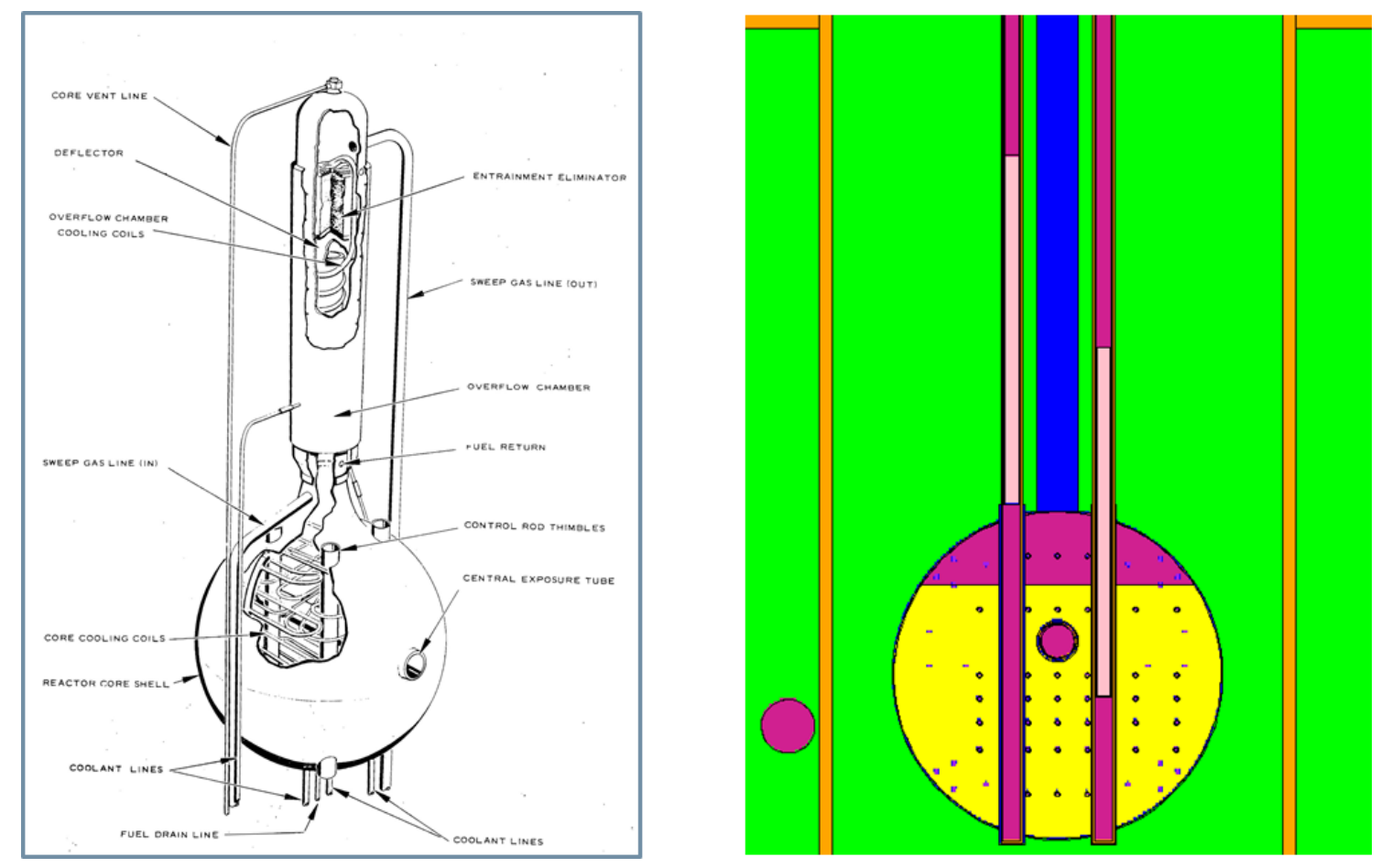

Figure 2 Reactor core section from official blueprint (Left) and as implemented in the code (Rigth). 


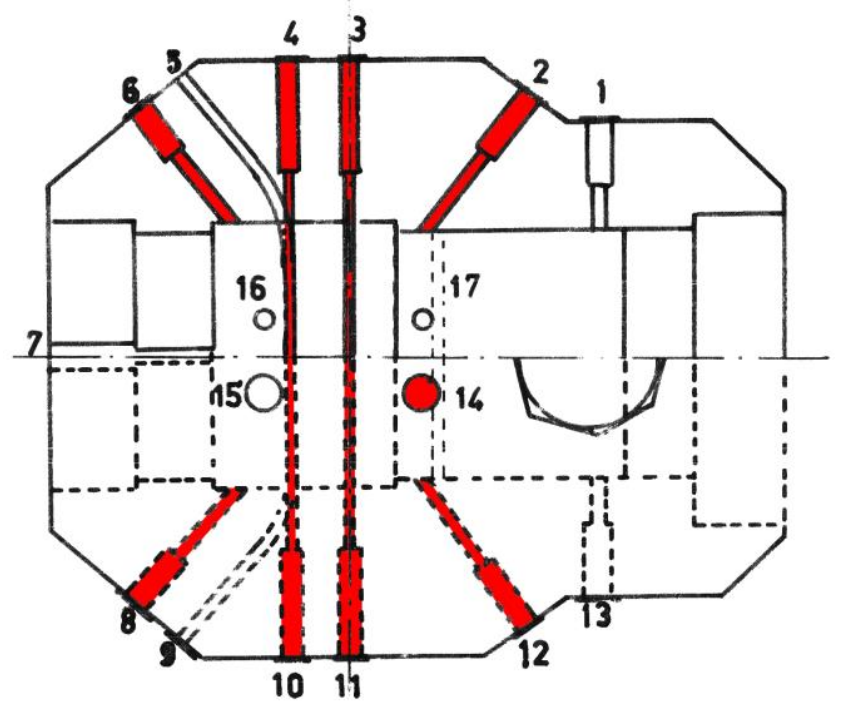

Figure 3 Reactor horizontal section with numbered L-54M exposure channels. The implemented ones are evidenced in red, namely Channels 3-11, 4-10, 6-8, and 14. 


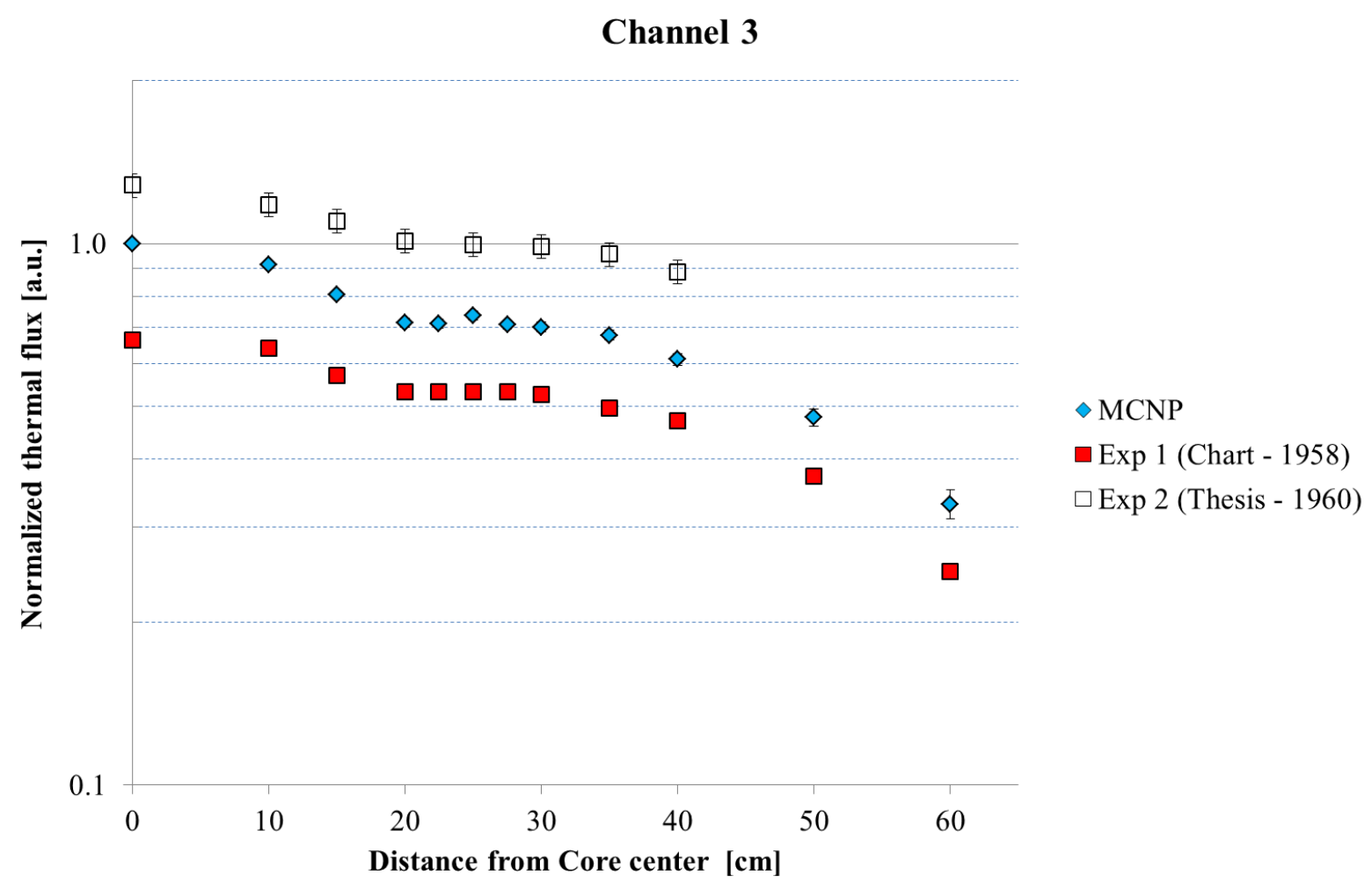

Figure 4 Comparison between the simulated normalized thermal neutron flux in the central exposure channel (namely, Channel 3) and two available experimental datasets, namely $\operatorname{Exp} 1$ and $\operatorname{Exp} 2$ (21,23), expressed in arbitrary units, referred to $0 \mathrm{~cm}$ MCNP value. Atomic International charts datasets are provided without associated error. 


\section{Tables}

Table 1 Simulated (this work) reactivity values, calculated with ENDF and JEFF crosssection libraries and normalized on the literature data $(4,22)$.

\begin{tabular}{cccc}
\hline & MCNP & MCNP & Literature \\
& {$[$ ENDF/B-VII.0] } & {$[$ JEFF-3.2] } & \\
\hline Supercritical reactivity $\left(\mathbf{2 0}^{\circ} \mathbf{C}\right)$ & $0.681 \pm 0.004$ & $0.890 \pm 0.004$ & 1 \\
Total rod worth & $1.003 \pm 0.003$ & $0.951 \pm 0.003$ & $1 \pm 0.022$ \\
\hline
\end{tabular}


Table 2 Simulated (this work) control rods worth, calculated with ENDF cross-section libraries and normalized on the literature data (22).

MCNP Literature

[ENDF/B-VII.0]

\begin{tabular}{lll}
\hline $\mathbf{1}^{\text {st }}$ rod & $0.928 \pm 0.012$ & $1 \pm 0.029$ \\
$\mathbf{2}^{\text {nd }}$ rod & $0.929 \pm 0.012$ & $1 \pm 0.029$ \\
$\mathbf{3}^{\text {rd }}$ rod & $0.935 \pm 0.012$ & $1 \pm 0.011$ \\
$\mathbf{4}^{\text {th }}$ rod & $0.952 \pm 0.012$ & $1 \pm 0.018$ \\
\hline
\end{tabular}


Table 3 Comparison between MCNP simulated and experimental activity concentration (expressed in arbitrary units, referred to $0 \mathrm{~cm}$ experimental value) of ${ }^{152} \mathrm{Eu}$ in L-54M graphite reflector (28).

\begin{tabular}{ccc}
\hline $\begin{array}{c}\text { Distance from } \\
\text { core surface [cm] }\end{array}$ & $\begin{array}{c}\text { Activity concentration } \\
\text { MCNP [a.u.] }\end{array}$ & $\begin{array}{c}\text { Activity concentration } \\
\text { Experimental [a.u.] }\end{array}$ \\
\hline $\mathbf{0}$ & $0.823 \pm 6.2 \%$ & $1 \pm 7.4 \%$ \\
$\mathbf{8 0}$ & $0.087 \pm 4.6 \%$ & $0.135 \pm 6.7 \%$ \\
$\mathbf{1 2 0}$ & $0.007 \pm 5.6 \%$ & $0.016 \pm 7.3 \%$ \\
\hline
\end{tabular}

